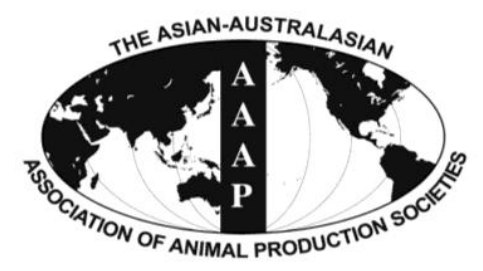

Asian-Aust. J. Anim. Sci.

Vol. 26, No. 3 : 334-342 March 2013

http://dx.doi.org/10.5713/ajas.2012.12564

www.ajas.info

pISSN 1011-2367 elSSN 1976-5517

\title{
Effects of Hormones on the Expression of Matrix Metalloproteinases and Their Inhibitors in Bovine Spermatozoa
}

\author{
Sang-Hwan Kim ${ }^{2, a}$, Young-Seon Song ${ }^{3, a}$, Sue-Yun Hwang ${ }^{3}$, Kwan-Sik Min ${ }^{3}$ and Jong-Taek Yoon ${ }^{1,2, *}$ \\ ${ }^{1}$ Department of Animal Life Science, Hankyong National University, Anseong 456-749, Korea
}

\begin{abstract}
Proteases and protease inhibitors play key roles in most physiological processes, including cell migration, cell signaling, and cell surface and tissue remodeling. Among these, the matrix metalloproteinase (MMPs) pathway is one of the most efficient biosynthetic pathways for controlling the activation of enzymes responsible for protein degradation. This also indicates the association of MMPs with the maturation of spermatozoa. In an attempt to investigate the effect of MMP activation and inhibitors in cultures with various hormones during sperm capacitation, we examined and monitored the localization and expression of MMPs (MMP-2 and MMP9), tissue inhibitors of metalloproteinases (TIMP-2 and TIMP-3), as well as their expression profiles. Matured spermatozoa were collected from cultures with follicle-stimulating hormone (FSH), luteinizing hormone (LH), and Lutalyse at $1 \mathrm{~h}, 6 \mathrm{~h}, 18 \mathrm{~h}$, and $24 \mathrm{~h}$. ELISA detected the expression of MMP-2, MMP-9, TIMP-2, and TIMP-3 in all culture media, regardless of medium type (FSHsupplemented fertilization Brackett-Oliphant medium (FFBO), LH-supplemented FBO (LFBO), or Lutalyse-supplemented FBO (LuFBO)). TIMP-2 and TIMP-3 expression patterns decreased in LFBO and LuFBO. MMP-2 and MMP-9 activity in FBO and FFBO progressively increased from $1 \mathrm{~h}$ to $24 \mathrm{~h}$ but was not detected in LFBO and LuFBO. The localization and expression of TIMP-2 and TIMP-3 in sperm heads was also measured by immunofluorescence analysis. However, MMPs were not detected in the sperm heads. MMP and TIMP expression patterns differed according to the effect of various hormones. These findings suggest that MMPs have a role in sperm viability during capacitation. In conjunction with hormones, MMPs play a role in maintaining capacitation and fertilization by controlling extracellular matrix inhibitors of sperm. (Key Words: Bovine, Spermatozoa, MMPs, TIMPs, Capacitation)
\end{abstract}

\section{INTRODUCTION}

In in vitro fertilization, sperm capacitation is as important as oocyte maturation. Sperm cells must undergo capacitation, and those that do not go through the maturation stage do not have the capacity to fertilize oocytes (Chang, 1951). Spermatozoa become capacitated in vivo by interacting with various hormones and stimuli inside the female reproductive tract before encountering the egg (Yanagimachi et al., 1994). The capacitated spermatozoon then initiates more physiological processes before fertilization (Frayne et al., 1997; Barrett et al., 1998). When the spermatozoa reach the matured oocyte, the

\footnotetext{
* Corresponding Author: Jong Taek Yoon. Tel: +82-31-670-5255, Fax: +82-31-675-8265, E-mail: jtyoon@hknu.ac.kr

${ }^{2}$ Institute of Genetic Engineering, Hankyong National University, Anseong 456-749, Korea.

${ }^{3}$ Graduate School of Bio and Information Technology, Hankyong National University, Anseong 456-749, Korea.

${ }^{\mathrm{a}}$ These authors contributed equally to this work.

Submitted Oct. 10, 2012; Accepted Dec. 1, 2012; Revised Dec. 17, 2012
}

cumulus cells and zona pellucida surrounding the eggs are dissolved by hydrolytic enzymes distributed in the acrosomal vesicle of spermatozoa (Kohno et al., 1998; Tulsiani et al., 1998; Yamagata et al., 1998). During the fertilization process, specific protein-degrading enzymes are added to the acrosomal membrane of spermatozoa in the epididymis, and spermatozoa are capacitated by the uterine environment and hormones, thereby completing the acrosome reaction (Phelps et al., 1990; Barrett et al., 1998). However, very little is known about the effect of the extracellular matrix on the acrosome reaction of sperm from hormones. To date, many studies have been performed on the expression and function of MMPs and TIMPs in the maturation and fertilization of reproductive cells. It is believed that a very important function of MMP-2 and MMP-9 is in cell remodeling processes in the male and female reproductive system (Woessner, 1994; Hulboy et al., 1997; Xu et al., 2000). MMPs facilitates proteolytic activity of cellular substrates, and during spermatogenesis, they have important roles in the reconstruction of sperm cellular morphology (Longin et al., 2001, 2002; Slongo et al., 2002). 
In particular, the necessity of breakdown of physical barriers in the fertilization process suggests that MMPs, along with their TIMPs, might be involved in the process (Salamonsen, 1996; Hulboy et al., 1997). Therefore, the MMP pathway during biosynthesis is one of the most appropriate pathways to control the activation of enzymes that cause protein degradation (Gunnarsson et al., 1999). Furthermore, MMPs might be associated with the maturation of spermatozoa. The purpose of this study was to investigate the expression pattern of MMPs and TIMPs in in vitro cultures of bovine sperm cells in hormonesupplemented media.

\section{MATERIAL AND METHODS}

\section{Semen samples}

Frozen Holstein semen samples were used for the present study. They were thawed for $20 \mathrm{~s}$ at $37^{\circ} \mathrm{C}$ to obtain vigorous spermatozoa and centrifuged for $15 \mathrm{~min}$ at $800 \times \mathrm{g}$ under a 95\%/45\% Percoll density gradient (Sigma, St Louis USA). The sperm pellet portion was diluted with BO medium containing $1 \mathrm{ml}$ of $5 \mathrm{mM}$ caffeine and centrifuged for $5 \mathrm{~min}$ at $1500 \mathrm{rpm}$. The concentration of sperm cells was adjusted to $5 \times 10^{6} \mathrm{sperm} / \mathrm{ml}$ using Brackett-Oliphant (BO) medium containing heparin and $3 \%$ BSA.

Spermatozoa culture: For better capacitation of spermatozoa during in vitro fertilization, the medium used by Brackett et al. (1975) was modified. The spermatozoa (final concentration of $5 \times 10^{6} \mathrm{sperm} / \mathrm{ml}$ ) were cultured in a 4-well dish containing BO medium with heparin $(10 \mu \mathrm{g} / \mathrm{ml})$ and $3 \% \mathrm{BSA}$ in a total volume of $500 \mathrm{ml}$ at $38.5^{\circ} \mathrm{C}$, in a $5 \%$ $\mathrm{CO}_{2}$ incubator for $1,6,18$, and $24 \mathrm{~h}$.

Hormones: To investigate the capacitation of spermatozoa and the expression of MMPs and TIMPs in the presence of hormones, follicle-stimulating hormone (FSH), luteinizing hormone $(\mathrm{LH})$, and Lutalyse ${ }^{\circledR}$ were added to final concentrations of $5 \mu \mathrm{g} / \mathrm{ml}$ each (Longin et al., 2002) and cultured for 1, 6, 18, and $24 \mathrm{~h}$. Fertilization BO (FBO) medium was used as the control.

\section{Analysis of spermatozoa viability}

The viability of spermatozoa was observed in wet mounts using phase-contrast microscopy $(400 \times)$ with a heated cover glass (warmed for $1 \mathrm{~min}$ at $37^{\circ} \mathrm{C}$ ).

Viability test using Hoechst 33258: The modified method described by de Leeuw et al. (1991) was used to test sperm viability. Six milliliters of Dulbecco's phosphatebuffered saline (PBS) containing $0.3 \%$ of BSA was mixed with $1 \mathrm{ml}$ of semen and centrifuged for $5 \mathrm{~min}$ at $800 \times \mathrm{g}$. The supernatant was removed, and the sperm concentration was adjusted to a final concentration of $3 \times 10^{6} \mathrm{cell} / \mathrm{ml}$. Then, 100 $\mu \mathrm{l}$ of the sperm pellet was mixed with $100 \mu \mathrm{g} / \mathrm{ml}$ of
Hoechst 33258 in a microtube and cultured for $3 \mathrm{~min}$ at $37^{\circ} \mathrm{C}$. Spermatozoa were fixed using $10 \%$ formalin, and spermatozoa heads were observed in wet mounts using AX70 fluorescence microscopy.

Analysis of acrosome condition in hormonesupplemented treatments: Acrosome condition was analyzed using the improved Coomassie Brilliant Blue (Bio-Rad, CA, USA) method described by de Leeuw et al. (1991). Sperm samples with a concentration of $3 \times 10^{6}$ sperm $/ \mathrm{ml}$ were centrifuged at $800 \times \mathrm{g}$. The supernatant was removed, and $1 \mathrm{ml}$ of $1 \times \mathrm{PBS}$ was added and centrifuged twice for $5 \mathrm{~min}$ at $500 \times \mathrm{g}$. The supernatant was removed, 2 $\mathrm{ml}$ of $3.7 \%$ formalin was added, and the pellet was fixed for $40 \mathrm{~min}$. Then, the pellet was centrifuged again for $5 \mathrm{~min}$ at $500 \times \mathrm{g}$, and the supernatant was removed.

The sperm pellet was diluted with $1 \mathrm{ml}$ of $1 \times \mathrm{PBS}$, and $100 \mu \mathrm{l}$ of this solution was placed on a glass slide and dried at room temperature. The slide was stained with $0.25 \%$ Coomassie Brilliant Blue for $5 \mathrm{~min}$. The degree of staining was observed by phase contrast microscopy $(400 \times)$ to determine the morphology of acrosomes. Acrosomes stained blue were considered normal, while the unstained acrosomes were considered abnormal. The normal percentage was based on 200 sperm cells.

\section{Preparation of samples}

Extraction of total protein from sperm cells and slide preparation: To extract proteins from sperm cells, $5 \times 10^{6}$ $\mathrm{sperm} / \mathrm{ml}$ of sperm cells were centrifuged for $5 \mathrm{~min}$ at 5,000 $\mathrm{rpm}$. The supernatant was removed, and $1 \mathrm{ml}$ of $1 \times \mathrm{PBS}$ was added and then centrifuged again at 5,000 rpm. After removing the supernatant, the pellet was mixed with $100 \mu \mathrm{l}$ of PRO-PREP ${ }^{\mathrm{TM}}$ (Intron Biotechnology, Gyeonggi-do KOR) and centrifuged at $13,000 \mathrm{rpm}$ at $4{ }^{\circ} \mathrm{C}$ for $30 \mathrm{~min}$. The sediment was stored at $-20^{\circ} \mathrm{C}$ for later use.

Treatment of spermatozoa culture media: The culture medium without sperm cells was centrifuged in $1.5-\mathrm{ml}$ tubes. After centrifugation, the supernatant was removed, and the sediment was stored at $-20^{\circ} \mathrm{C}$ for later use.

Slide preparation for immunoassay of spermatozoa: Sperm cells in culture media were centrifuged at 4,000 rpm for $5 \mathrm{~min}$. The supernatant was removed, and the sediment washed with $1 \times \mathrm{PBS}$ and fixed with $4 \%$ formaldehyde on a poly-L-lysine-coated slide at $4^{\circ} \mathrm{C}$ for $30 \mathrm{~min}$. The slide was purified using $0.2 \%$ Triton X-100. Tris-buffer (25 mM TrisHCL, $150 \mathrm{mM} \mathrm{NaCl}$ ) was mixed with $0.1 \%$ Tween 20 to prepare TTBS for washing twice. The slide was covered with a coverslip and stored at $4^{\circ} \mathrm{C}$.

\section{Analysis of MMP-2 and MMP-9 activity}

Zymography: To analyze MMPs, $20 \mathrm{mg}$ of total sperm protein and medium (sperm cultured medium) were mixed 
with $2 \mu \mathrm{l} / 10 \mu \mathrm{l} \mathrm{FOZ} \mathrm{loading} \mathrm{buffer} \mathrm{(5 \%} \mathrm{bromophenol} \mathrm{blue,}$ $10 \%$ SDS, $2 \%$ glycerol) and reacted on ice for $5 \mathrm{~min}$. This sample was subjected to electrophoretic analysis using SDS-PAGE containing $100 \mathrm{mg} / \mathrm{ml}$ of gelatin for $90 \mathrm{~min}$ at $150 \mathrm{~V}$. After electrophoresis, protein renaturation of the gel was induced twice using renaturation buffer $(2.5 \%$ Triton $\mathrm{X}-100,1 \times \mathrm{PBS}$ ) for $20 \mathrm{~min}$, and the gel was washed with sterilized water for $20 \mathrm{~min}$. After renaturation, the zymography reaction buffer (1 M Tris-HCL pH 7.5, $5 \mathrm{M}$ $\mathrm{NaCl}, 1 \mathrm{M} \mathrm{CaCl} 2,0.2 \mathrm{mM} \mathrm{ZnCl} 2,0.2 \%$ Triton X-100, $0.02 \% \mathrm{NaN}_{3}$ ) was mixed at $37^{\circ} \mathrm{C}$ for $18 \mathrm{~h}$ for reaction. After the reaction, the zymography gel was stained with Coomassie Brilliant Blue for $1 \mathrm{~h}$. Then, the destained area was analyzed.

Protein expression patterns of MMP-2, MMP-9, TIMP-2, and TIMP-3

ELISA: For quantification of specific protein from the culture medium and sperm protein, a primary antibody was applied to a 96-well ELISA plate at $4^{\circ} \mathrm{C}$ for $1 \mathrm{~d}$, washed twice using washing buffer $(1 \times \mathrm{PBS}$ with $2.5 \%$ Triton $\mathrm{X}$ 100 ), and blocked using $1 \%$ skim milk blocking solution at $4^{\circ} \mathrm{C}$ for $24 \mathrm{~h}$. After washes with the washing buffer, immune reactions were detected using secondary antibodies for $2 \mathrm{~h}$, and substrate solution (R\&D Systems, USA) was added for the reaction. To stop the reaction, $1 \mathrm{M} \mathrm{NH}_{2} \mathrm{SO}_{4}$ was used, and absorbency was measured at $450 \mathrm{~nm}$.

Immunofluorescence: Each sperm-treated slide was treated twice with $0.2 \%$ Triton $\mathrm{X}-100$ at room temperature and washed 3 times using TTBS $(1 \times$ Tris, $1 \times \mathrm{NaCl}$ Tris, $1 \times \mathrm{NaCl}, 0.02 \%$ Tween 20$)$. Normal horse serum $(5 \%)$ and $1 \%$ goat serum were mixed with $1 \times \mathrm{PBS}$ for use as a blocking solution at room temperature for $1 \mathrm{~h}$.

Primary antibodies for TIMP-2 and TIMP-3 were diluted (1:200) with the blocking solution, and the antigenantibody reaction was induced at $4^{\circ} \mathrm{C}$ for $24 \mathrm{~h}$. Then, sperm-treated slide was washed 4 times with $1 \times \mathrm{PBS}$.

A

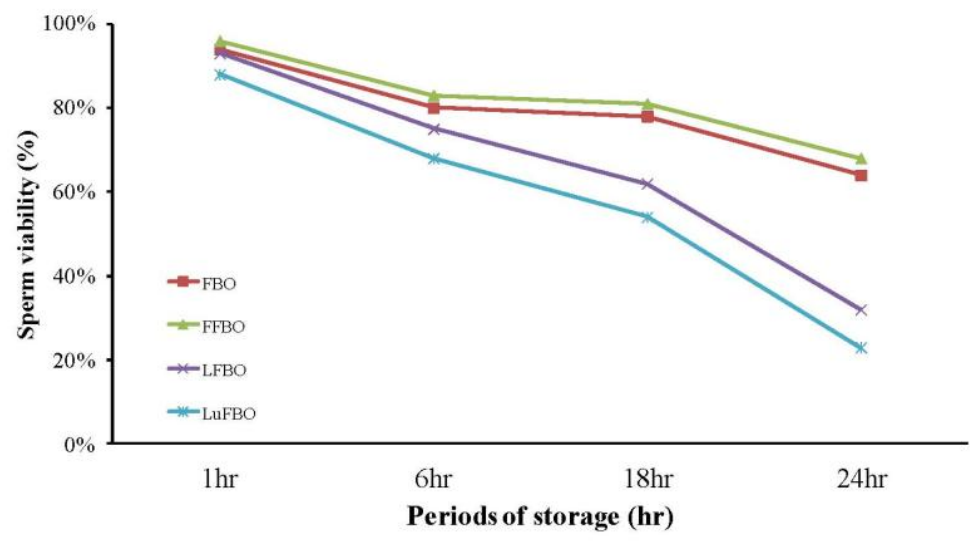

B

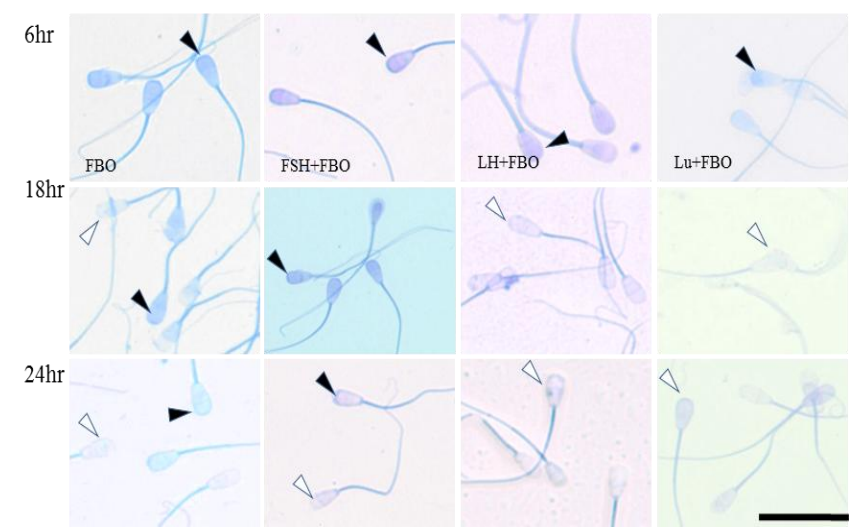

a

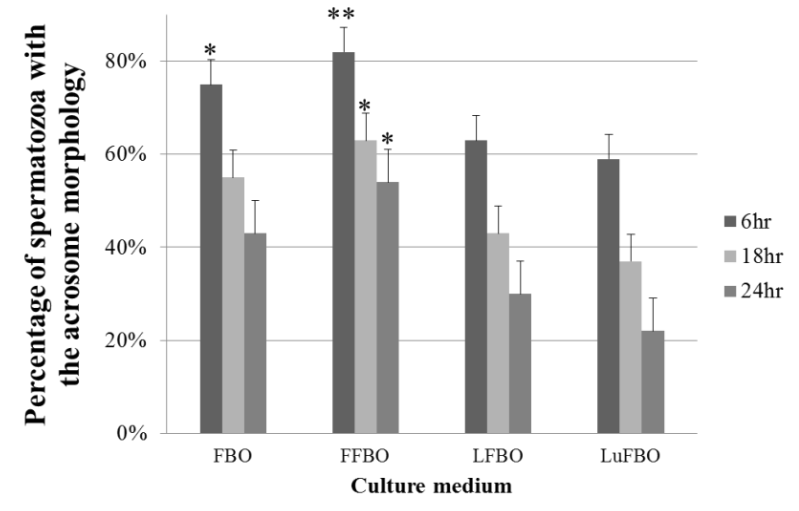

Figure 1. Effect of different hormones treated for survival ability spermatozoa and acrosome reacted under hormones culture for $1,6,18$ and $24 \mathrm{~h}$. **** Different letters within the same column represent a significant difference $(\mathrm{p}<0.05)$. Black arrows indicate normal acrosome detection. And white arrows indicate abnormal acrosome detection. A: Hoechst33258 analysis of sperm viability under hormones culture for 1, 6, 18 and $24 \mathrm{~h}$. Stained spermatozoa were considered dead and the unstained alive. (Graph of survival ability spermatozoa), B: Effects of hormones on acrosome morphology spermatozoa culture for 6, 18 and 24 h, B-a: Percentage of acrosome morphology. FBO: Control, FFBO: FSH treated culture medium, LFBO: LH treated culture medium, LuFBO: Lutalyse treated culture medium. 
Secondary antibodies Alexa-594 and Alexa-488 were applied at $37^{\circ} \mathrm{C}$ for $30 \mathrm{~min}$ and washed 3 times with $1 \times$ PBS for $5 \mathrm{~min}$. The counter stain used for the nucleus and cytoplasm was Hoechst 33342. The slides were mounted using H-1000 and observed by fluorescence microscopy.

Western blot: Each sample containing $50 \mu \mathrm{g}$ of protein was separated by $13 \%$ SDS-polyacrylamide gel and transferred to a PVDF membrane (Bio-Rad, CA, USA). The membrane was blocked with $5 \%$ blocking buffer overnight at $4^{\circ} \mathrm{C}$. The membrane was washed once for $10 \mathrm{~min}$ with TBS-T buffer $(0.1 \% \mathrm{v} / \mathrm{v}$ Tween $20,50 \mathrm{mM}$ Tris-HCl, 200 $\mathrm{mM} \mathrm{NaCl}$ ). The membrane was then incubated for $2 \mathrm{~h}$ with anti-rabbit TIMP-2,3 polyclonal antibodies (diluted 1:1,000; Abcam). After binding, the membranes were washed 3 times with $1 \times$ TBS-T buffer for $15 \mathrm{~min}$ each and then incubated for $2 \mathrm{~h}$ with HRP-conjugated anti-goat secondary antibodies (diluted 1:5,000). The detection was carried out using the ECL detection kit (Invitrogen, NY, USA) in a dark room after a 5-min incubation. The detection reagent was drained, and the membrane was exposed to a sheet of diagnostic film in a film cassette for 1 to $30 \mathrm{~min}$.

\section{Statistical analysis}

Data were subjected to $t$-test and general linear model analysis using the Statistical Analysis System (SAS Institute, version 9.4, Cary, NC, USA). Differences among treatments were determined by using Duncan's multiple range tests. The statistical significance was established at $\mathrm{p}<0.05$.

\section{RESULTS}

\section{Analysis of spermatozoa viability in hormone- supplemented medium}

Viabilities of spermatozoa when cultured in hormonesupplemented media are shown in Figure 1A. The viability of spermatozoa in the control medium (FBO) was 94\% when cultured for $1 \mathrm{~h}$, but it decreased to $80 \%, 78 \%$, and $64 \%$ when cultured for $6 \mathrm{~h}, 18 \mathrm{~h}$, and $24 \mathrm{~h}$, respectively. A similar result was obtained in FSH-supplemented (FFBO) culture medium $(96 \%, 83 \%, 81 \%$, and $68 \%$ respectively). However, when cultured in LH-supplemented medium (LFBO) for $6 \mathrm{~h}, 18 \mathrm{~h}$, and $24 \mathrm{~h}$, the viabilities were 93\%, $75 \%, 62 \%$, and $32 \%$, respectively, while viabilities in Lutalyse-supplemented medium (LuFBO) were 88\%, 68\%, $54 \%$, and $23 \%$, respectively. Viabilities in LuFBO decreased rapidly when cultured for more than $1 \mathrm{~h}$ compared with those in FBO and FFBO.

\section{Analysis of acrosome morphology}

Acrosome morphology in hormone-supplemented culture for 6,18 , and $24 \mathrm{~h}$ is shown in Figure 1B. The percentage of normal acrosomes when cultured in hormonesupplemented medium is shown in Figure 1B-a. In the
A

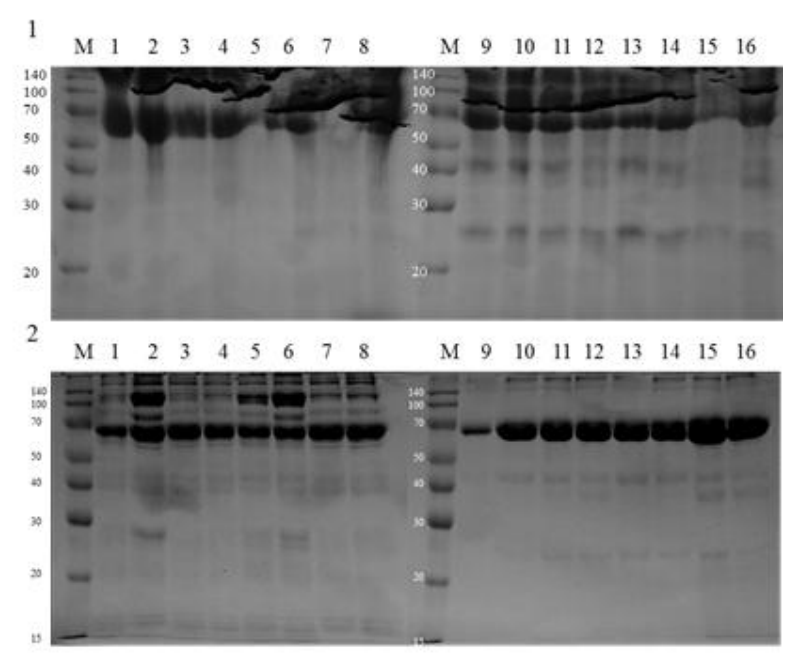

B

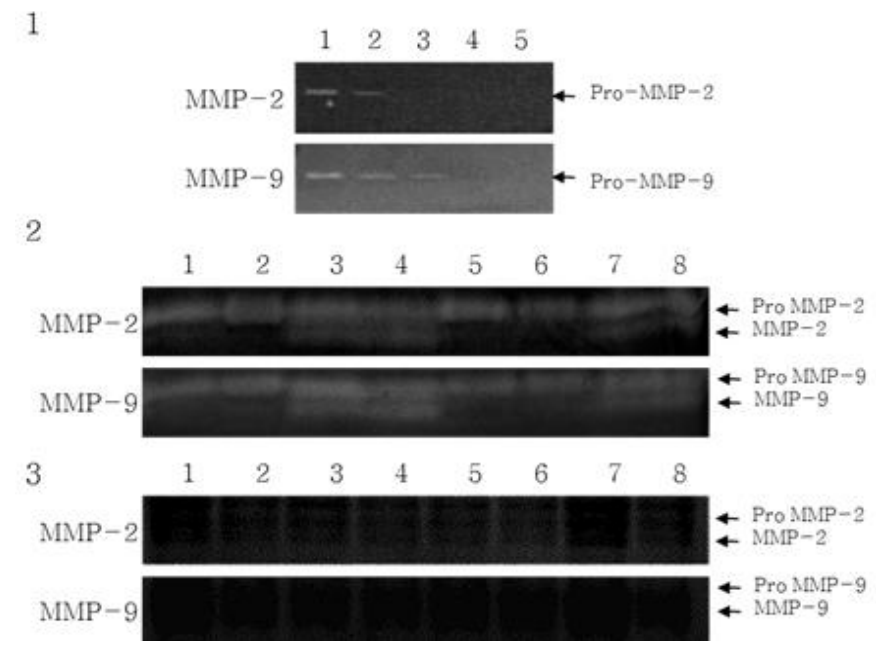

Figure 2. Protein profile and MMPs activity analyzed of cultured medium and bovine spermatozoa protein. A: Protein profile during FBO and hormone treatment in sperm and culture medium. A-1: Culture mediums. FBO control: (Lane 1. $1 \mathrm{~h}, \mathrm{Lane} 2.6 \mathrm{~h}, \mathrm{Lane} 3.18 \mathrm{~h}$, Lane 4.24 h), FSH treatment: (Lane 5.1 h, Lane 6.6 h, Lane 7. 18 h, Lane 8. 24 h), LH treatment: (Lane 9. 1 h, Lane 10. 6 h, Lane 11. 18 h, Lane 12. 24 h), Lutalyse treatment (Lane 13. 1 h, Lane 14. 6 h, Lane 15.18 h, Lane 16. 24 h). A-2: Sperm proteins. FBO control: (Lane 1. 1 h, Lane 2. 6 h, Lane 3. 18 h, Lane 4.24 h), FSH treatment: (Lane 5. 1 h, Lane 6. 6 h, Lane 7. 18 h, Lane 8. 24 h), LH treatment: (Lane $9.1 \mathrm{~h}$, Lane 10. 6 h, Lane 11. 18 h, Lane 12. 24 h), Lutalyse treatment (Lane 13. 1 h, Lane 14. 6 h, Lane 15. 18 h, Lane 16. 24 h). B: Zymograms of MMP activities in bovine sperm conditioned media collected at 1,6,18 and 24 h of culture. B-1: Non treatment group: (Lane $1.1 \mathrm{~h}$, Lane $2.6 \mathrm{~h}$, Lane $3.18 \mathrm{~h}$, Lane $4.24 \mathrm{~h}$ ), B-2: Activity MMP2,9 analysis during FBO \& FSH treatment. FBO control: (Lane 1. 1 h, Lane 2. 6 h, Lane 3.18 h, Lane 4.24 h) FSH treatment: (Lane 5. 1 h, Lane 6. 6 h, Lane 7. 18 h, Lane 8. 24 h) B-3: Activity MMP2,9 analysis during LFBO and FSH treatment. LH treatment: (Lane 1. 1 h, Lane 2. 6 h, Lane 3. 18 h, Lane 4. 24 h). Lutalyse treatment: (Lane 5. 1 h, Lane 6. 6h, Lane 7. 18h, Lane 8. $24 \mathrm{~h}$ ). 

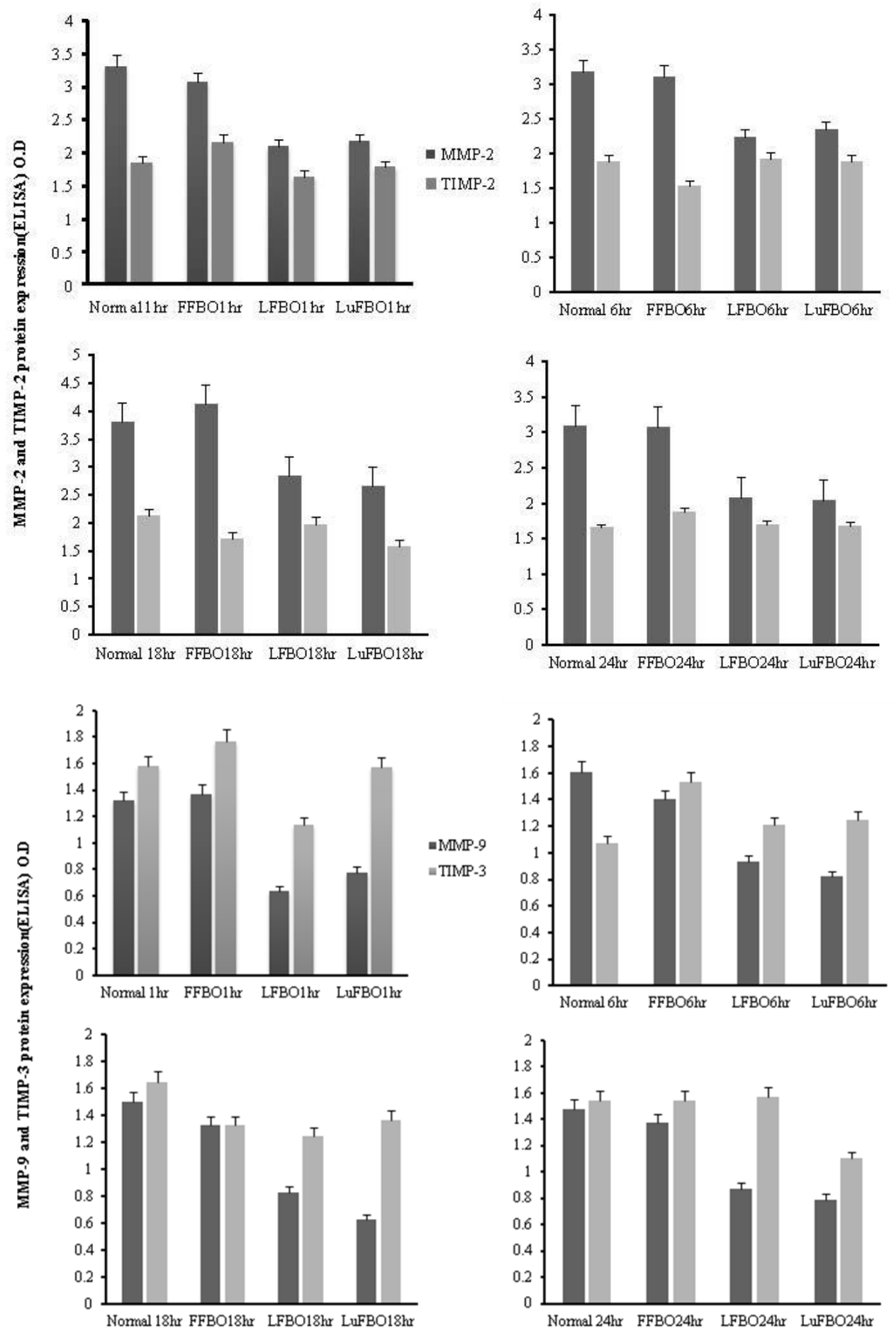

Figure 3. ELISA analysis of MMP-2, 9 and TIMP-2, 3 in bovine sperm conditioned media collected at 1, 6, 18 and $24 \mathrm{~h}$ of culture. Normal: FBO control, FFBO: FSH treatment, LFBO: LH treatment, LuFBO: Lutalyse treatment.

control medium, from 6 to $18 \mathrm{~h}$ of culture, it was $75 \%$ and $55 \%$, while in FFBO, it was $82 \%$ and $63 \%$; however, when cultured for $24 \mathrm{~h}$, it decreased to $43 \%$ in the control and $54 \%$ in FFBO. In LH- and Lutalyse-supplemented media, most sperm cells were abnormal from 6 to $24 \mathrm{~h}$ of culture (in $\mathrm{LFBO} 63 \%, 43 \%$, and 30\%, respectively and in LuFBO $59 \%, 37 \%$, and $22 \%$, respectively). Similar results were obtained for sperm viability. The results showed that sperm cells responded differently to hormones and sperm proteins out flowed rapidly (acrosome reaction).

Protein expression patterns in spermatozoa and culture medium

Treatment-wise electrophoresis results of protein 
expression patterns in spermatozoa and culture media are shown in Figure 3. More proteins were expressed in spermatozoa in LFBO and LuFBO than in the control and FFBO (Figure 2A-1). However, more proteins were expressed from spermatozoa in the control group and FFBO than in LFBO and LuFBO (Figure 2A-2).

\section{Zymography analysis of MMP-2 and MMP-9 activity}

Zymography results for the analysis of MMP-2 and MMP-9 activities by length of time of spermatozoa culture are shown in Figure 2B. In FBO and FFBO, the expression patterns of non-activated pro-MMP-2 and pro-MMP-9 did not differ by culture time, but after $1 \mathrm{~h}$ of culture, only the non-activated pro-MMP was expressed (Figure 2B-2), while active MMP-2 and MMP-9 were expressed from $6 \mathrm{~h}$ of culture and strongly expressed after 18 and $24 \mathrm{~h}$ of culture. However, pro-MMPs and MMPs were not expressed in LFBO and LuFBO (Figure 2B-3).

\section{Expression of MMP-2, 9 and TIMP-2, 3 proteins}

The results for MMP-2 and MMP-9 activity and protein expression patterns of TIMP-2 and TIMP-3 are shown in Figure 3. MMP-2 expression was higher in the control and in FFBO than in LFBO and LuFBO. It was consistently expressed from 6 to $18 \mathrm{~h}$ of culture.

In all treatments, MMP-2 was expressed the most at 18 $\mathrm{h}$, and the highest expression was found in FFBO compared to other treatments. A similar trend was noted in the expression of TIMP-2, but the expression rate was relatively lower than that of MMP-2. In all treatments, TIMP-3 expression was higher than MMP-9 expression. In the control and in FFBO, MMP-9 expression was the same. Maximum expression was during $1 \mathrm{~h}$ of culture. It decreased by $6 \mathrm{~h}$ and increased again after $24 \mathrm{~h}$. In the treatments of LFBO and LuFBO, MMP-9 was expressed at a lower level during the entire culture, but the expression rate of TIMP-3 increased gradually. Overall, MMP-2 expression was higher than MMP-9 expression, while expression of TIMP-2 was lower than that of TIMP-3.

\section{Patterns and localization of TIMP-2 and TIMP-3 expressions in spermatozoa}

The patterns and localization of TIMP-2 and TIMP-3 expression in spermatozoa by different treatments and by culture time are shown in Figure 4. The expression of TIMP-2 and TIMP-3, the inhibitors of MMP-2 and MMP-9, was distinguished in the head of spermatozoa and was not detected in other areas, indicating that TIMP-2 and TIMP-3 are expressed in the sperm head (Figure 4A). The expression of TIMP-2 in spermatozoa protein was similar to that in the culture medium, and it was expressed more in FBO and FFBO than in LFBO and LuFBO.

In $\mathrm{FBO}$ and $\mathrm{FFBO}$, the expression was distinguished in the head of the spermatozoa, while it was not detected at all in LFBO and LuFBO. After $18 \mathrm{~h}$ of culture, it decreased drastically in FBO. A weak expression was noted in LFBO, which decreased after $18 \mathrm{~h}$ of culture (Figure 4B). In FFBO, TIMP-2 was continuously expressed from 6 to $24 \mathrm{~h}$ of culture but was not detected in LuFBO (Figure 4C-1).

The TIMP-3 expression pattern was similar to that in culture media: TIMP-3 expression was higher in FBO and FFBO. In LFBO, the TIMP-3 expression rate was higher than that in other culture media. However, in LuFBO, TIMP-3 expression was higher in culture media than in spermatozoa. When comparing expression rates by hormonal treatments, TIMP-3 expression was higher in FBO and FFBO than in LFBO and LuFBO (Figure 4B).

The same trend was noted in immunofluorescence analysis as with the protein expression, but in FBO, FFBO, and LFBO, the expression of TIMP-3 was distinguished in the head of spermatozoa. However, in LuFBO, protein expression was observed after $18 \mathrm{~h}$ of culture but not at $6 \mathrm{~h}$ and $24 \mathrm{~h}$ of culture. The expression of TIMP-3 in FBO, FFBO, and LFBO was the lowest at $18 \mathrm{~h}$ of culture and the highest at $6 \mathrm{~h}$ and $24 \mathrm{~h}$ of culture. In LuFBO, there was no TIMP-3 expression at $6 \mathrm{~h}$ and $24 \mathrm{~h}$ of culture, and weak expression was noted at $18 \mathrm{~h}$ of culture (Figure $4 \mathrm{C}-2$ ).

\section{DISCUSSION}

During spermatogenesis, specific protein-degrading enzymes used for fertilization are added to the acrosomal membrane of spermatozoa in the epididymis (Barrett et al., 1998). Sperm capacitation is enhanced by the uterine environment and hormones, which completes the acrosome reaction (Phelps et al., 1990; Suarez, 2008). In this study, we analyzed the viability of spermatozoa cultured with hormones. The viability of spermatozoa in the FFBO culture medium was $96 \%$ when cultured for $1 \mathrm{~h}$, but it decreased to $83 \%, 81 \%$, and $68 \%$ when cultured for $6 \mathrm{~h}, 18$ $\mathrm{h}$, and $24 \mathrm{~h}$, respectively. However, when cultured in LHsupplemented medium (LFBO) for $6 \mathrm{~h}, 18 \mathrm{~h}$, and $24 \mathrm{~h}$ viabilities were $93 \%, 75 \%, 62 \%$, and $32 \%$, respectively, while viabilities in LuFBO were $88 \%, 68 \%, 54 \%$, and $23 \%$, respectively. The pattern of normal acrosome morphology was the same as the viability pattern of spermatozoa. These results suggest that hormones play a role in maintaining normal acrosomal morphology and spermatozoa viability.

Sperm physiological and capacitation processes are completed through the renaturation of cell membranes caused by the interaction of several proteinases, inhibitors, and hormones (Barrett et al., 1998; Mruk et al., 1997, 2003; Wong et al., 2000; Chung et al., 2001). MMP-2, MMP-9, TIMP-2, and TIMP-3 have important roles in cell remodeling processes in the male reproductive system (Ray et al., 1994; Robinson et al., 2001). MMPs facilitate 
A
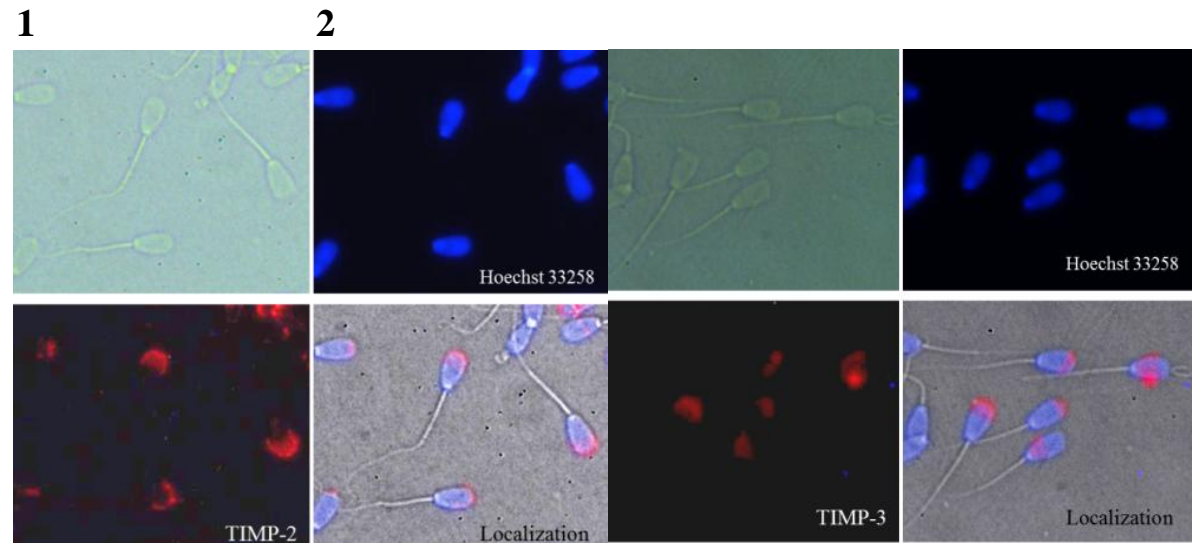

B

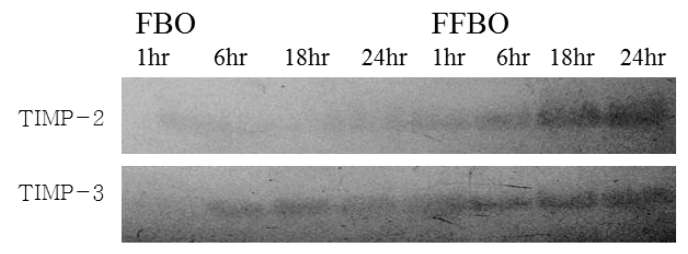

$42 \mathrm{kDa}$

$56 \mathrm{kDa}$

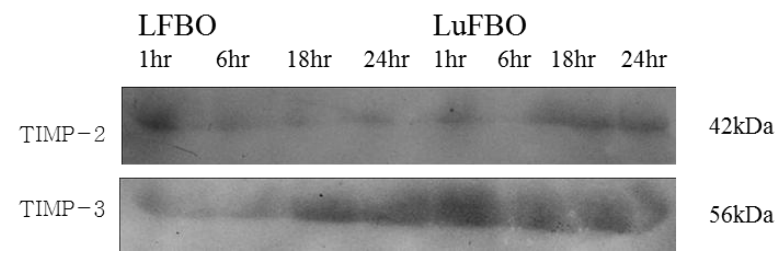

C
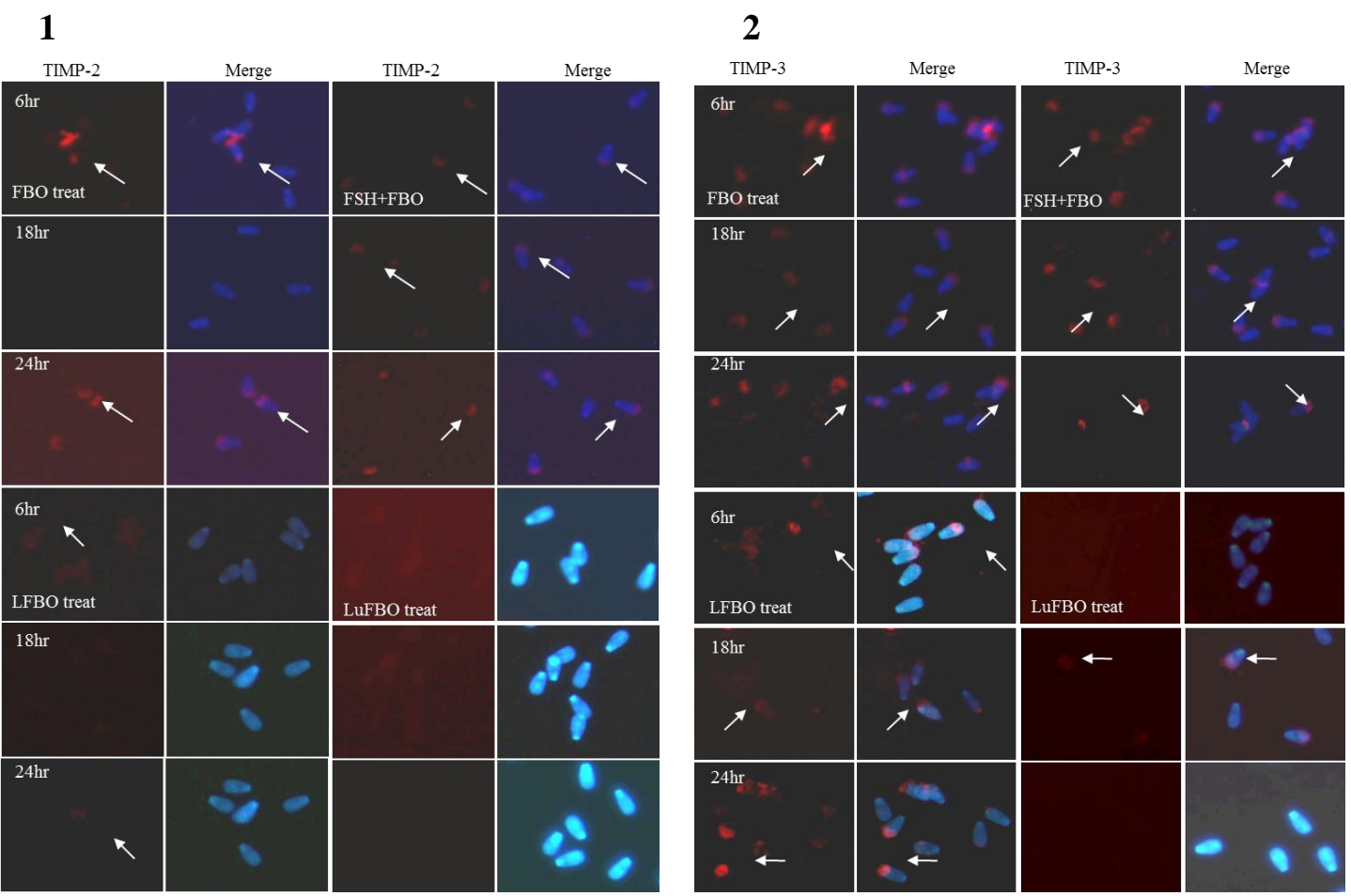

Figure 4. Expression and localization of TIMP-2,3 protein in bovine sperm. White arrows indicate aTIMP-2 and 3 protein detection. A: Immuno-localization of TIMP-2,3 protein in spermatozoa. A-1: TIMP-2, A-2: TIMP-3. B: Western-blot of TIMP-2, 3. C: Immunofluorescence for TIMP-3 localization in sperm. C-1: TIMP-2, C-2: TIMP-3. 
proteolytic activity of cellular substrates, and during spermatogenesis, they have roles in the reconstruction of cellular morphology (Breitbart, 2004). Sang et al. (1990) reported that in rat Sertoli cell cultures, MMP-2 was detected and was suspected to contribute to the remodeling of the basement membrane during the development of seminiferous tubules and in the release of differentiating germ cells from the basal lamina. MMPs are suggested to be involved in the FSH-induced changes in Sertoli cells (Longin et al., 2001, 2002; Slongo et al., 2002). The results of our experiment observed that the protein expression patterns of MMP-2, MMP-9, TIMP-2, and TIMP-3 differed when FSH, LH, and Lutalyse were added, which signifies that hormones affect the expression of these 4 proteins. The effects of hormones on normal acrosomal morphology and protein expression patterns varied based on the type of hormone added and the time of culture, demonstrating the differences in MMP activation (Siu et al., 2004; Xia, et al., 2007, 2009).

The results of our experiment showed the uniform expression of MMP-2 and MMP-9, as observed when FSH was added. Distinct expression of TIMP-2 and TIMP-3 was also identified. The appearance of MMP-2 and MMP-9 was more activated in the sperm culture medium, while TIMP-2 and TIMP-3 were expressed less in the sperm proteins. We also observed that when LH and Lutalyse were added to the medium, MMP-2, MMP-9, TIMP-2, and TIMP-3 expressions were low, sperm cell morphology was abnormal, and sperm viability was low. This signifies that capacitation and proteinase processes of spermatozoa are affected by hormones. Our results are in concordance with the results of Longin et al. (2001, 2002) and Slongo et al. (2002) that FSH might have an effect on spermatozoa and induce MMP activation. We also observed that LH and Lutalyse have less effect on the successful activation of MMPs compared to FSH.

In conclusion, our results showed that during sperm capacitation, the expression patterns of MMPs and TIMPs vary according to culture time and the kind of hormones added to the culture media, suggesting that this has an important role in the fertilization processes.

\section{ACKNOWLEDGEMENTS}

This work was supported by a grant from the NextGeneration BioGreen 21 Program (No. PJ008028), Rural Development Administration, Korea.

\section{REFERENCES}

Barrett, A. J., N. D. Rowlings and J. F. Woessner. 1998. Handbook of Proteolytic Enzymes. Academic Press, London, UK.

Brackett, B. G. and G. Oliphant. 1975. Capacitation of rabbit spermatozoa in vitro. Biol. Reprod. 12:260-274.
Breitbart, H. 2004. Intracellular calcium regulation in sperm capacitation and acrosomal reaction. Mol. Cell Endocrinol. 187:139-144.

Chang, M. C. 1951. Fertilizing capacity of spermatozoa deposited into the fallopian tubes. Nature 168:697-698.

Chung, N. P. and C. Y. Cheng. 2001. Is cadmium chloride-induced inter-Sertoli tight junction permeability barrier disruption a suitable in vitro model to study the events of junction disassembly during spermatogenesis in the rat testis. Endocrinology 142:1878-1888.

de Leeuw, A. M., J. H. den Daas and H. Woelders. 1991. The fix vital stain method. Simultaneous determination of viability and acrosomal status of bovine spermatozoa. J. Androl. 12:112-118.

Frayne, J., J. A. Jury, H. L. Barker, A. C. Perry, R. Jones and L. Hall. 1998. Macaque MDC family of proteins: sequence analysis, tissue distribution and processing in the male reproductive tract. Mol. Hum. Reprod. 4:429-437.

Gunnarsson, M., I. Lecander and P. A. Abrahamsson. 1999. Factors of the plasminogen activator system in human testis. as demonstrated by in-situ hybridization and immunohistochemistry. Mol. Hum. Reprod. 5:934-940.

Hulboy, D. L., L. A. Rudolph and L. M. Matrisian. 1997. Matrix metalloproteinases as mediators of reproductive function. Mol. Hum. Reprod. 3:27-45.

Kohno, N., K. Yamagata, S. Yamada, S. Kashiwabara, Y. Sakai and T. Baba. 1998. Two novel testicular serine proteases, TESP1 and TESP2, are present in the mouse sperm acrosome. Biochem. Biophys. Res. Commun. 245:658-665.

Longin, J., P. Guillaumot, M. A. Chauvin, A. M. Morera and B. B. Le Magueresse. 2001. MT1-MMP in rat testicular development and the control of Sertoli cell proMMP-2 activation. J. Cell. Sci. 114:2125-2134.

Longin, J. and B. B. Le Magueressei. 2002. Evidence that MMP-2 and TIMP-2 are at play in the FSH-induced changes in Sertoli cells. Mol. Cell Endocrinol. 189:25-35.

Siu, M. K. and C. Y. Cheng. 2004. Interactions of proteases, protease inhibitors, and the beta1 integrin/laminin gamma3 protein complex in the regulation of ectoplasmic specialization dynamics in the rat testis. Biol. Reprod. 70:945-964.

Mruk, D. D., M. K. Siu, A. M. Conway, N. P. Lee, A. S. Lau and C. Y. Cheng. 2003. Role of tissue inhibitor of metallo proteases-1 in junction dynamics in the testis. J. Androl. 24:510-523.

Mruk, D., L. J. Zhu, B. Silvestrini, W. M. Lee and C. Y. Cheng. 1997. Interactions of proteases and protease inhibitors in Sertoli-germ cell co-cultures preceding the formation of specialized Sertoli-germ cell junctions in vitro. J. Androl. 18:612-622.

Phelps, B. M., D. E. Koppel, P. Primakoff and D. G. Myles. 1990. Evidence that proteolysis of the surface is an initial step in the mechanism of formation of sperm cell surface domains. J. Cell Biol. 111:1839-1847.

Ray, J. M. and W. G. Stetler-Stevenson. 1994. The role of matrix metalloproteases and their inhibitors in tumour invasion, metastasis and angiogenesis. Eur. Respir. J. 7:2062-2072.

Robinson, L. L., N. A. Sznajder, S. C. Riley and R. A. Anderson. 2001. Matrix metallo-proteinases and tissue inhibitors of metalloproteinases in human fetal testis and ovary. Mol. Hum. Reprod. 7:641-648.

Salamonsen, L. A. and D. E. Woolley. 1996. Matrix 
metalloproteinases in normal menstruation. Hum. Reprod. 11:124-133.

Sang, Q. X., M. Dym, and S. W. Byers. 1990. Secreted metalloproteinases in testicular cell culture. Biol. Reprod. 43:946-955.

Slongo, M. L., M. Zampieri and M. Onisto. 2002. Expression of matrix metalloproteases (MMP-2, MT1-MMP) and their tissue inhibitor (TIMP-2) by rat Sertoli cells in culture: implications for spermatogenesis. Biol. Chem. 383:235-239.

Suarez, S. S. 2008. Control of hyperactivation in sperm. Hum. Reprod. Update. 14:647-657.

Tulsiani, D. R., H. A. Abou, C. R. Loeser and B. M. Pereira. 1998. The biological and functional significance of the sperm acrosome and acrosomal enzymes in mammalian fertilization. Exp. Cell Res. 240:151-164.

Wong, C. C., S. S. Chung. J. Grima, L. J. Zhu, D. Mruk, W. M. Lee and C. Y. Cheng. 2000. Changes in the expression of junctional and nonjunctional complex component genes when inter-Sertoli tight junctions are formed in vitro. J. Androl. 21:227-237.
Woessner, J. F. Jr. 1994. The family of matrix metalloproteinases. Ann. NY. Acad. Sci. 732:11-21.

Xia, J., D. Reigada, C. H. Mitchell and D. Ren. 2007. CATSPER channel mediated $\mathrm{Ca}^{2+}$ entry into mouse sperm triggers a tailto-head propagation. Biol. Reprod. 77:551-559.

Xia, J. and D. Ren. 2009. Egg-coat proteins activate calcium entry into mouse sperm via CATSPER channels. Biol. Reprod. 80:1092-1098.

Xu, P., Y. L. Wang, S. J. Zhu, S. Y. Luo, Y. S. Piao and L. Z. Zhuang. 2000. Expression of matrix metalloproteinase-2, -9, and -14 , tissue inhibitors of metalloproteinase-1, and matrix proteins in human placenta during the first trimester. Biol. Reprod. 62:988-994.

Yamagata, K., K. Murayama, M. Okabe, K. Toshimori, T. Nakanishi, S. Kashiwabara and T. Baba. 1998. Acrosin accelerates the dispersal of sperm acrosomal proteins during acrosome reaction. J. Biol. Chem. 273:10470-10474.

Yanagimachi, R. 1994. Mammalian Fertilization, In The Physiology of Reproduction. 2nd edition. Edited by E. Knobil, and J. D. Neill. Raven. pp. 189-315. 